\title{
Uma rede passa pelo currículo: difração e modos de existência na política curricular
}

\author{
A network passes through curriculum: diffraction and modes of \\ existence in curriculum policy
}

\section{Una red pasa por el currículo: difracción y modos de existencia en la política curricular}

Thiago Ranniery'

Universidade Federal do Rio de Janeiro, Programa de Pós-graduação em Educação na Linha Currículo, Ensino e Diferença, Professor. https://orcid.org/0000-0003-4399-2663

\section{Ricardo Scofano Medeiros ${ }^{2}$}

Universidade Federal do Rio de Janeiro, doutorando. https://orcid.org/0000-0002-9015-9853

Resumo: Este artigo emerge das intenções mais gerais de um projeto de pesquisa-intervenção realizado em parceria com a rede pública municipal de Niterói no mesmo momento em que o município experimenta responder as demandas legais da BNCC. A partir de rodas de conversas com professores de um curso de extensão com a finalidade de contribuir com a construção do referencial curricular da cidade, buscamos configurar uma reflexão teórica sobre política de currículo, modos de existência e difração. Situados como herdeiros da tradição que criticou a distinção entre implementação e formulação, desenvolvemos o argumento de que, ao invés de um currículo passar por uma rede, uma rede invariavelmente passa pelo currículo. Isto é, uma dinâmica topológica contínua ganha vida, envolvendo a variação espaço-temporal. Ancorados em estudos feministas e queers da ciência e da tecnologia e por intersecções da filosofia de Gilles Deleuze, indicamos que um diferimento constitutivo da política exibe uma difração do tempo e do espaço e, no mesmo passo, constitui emaranhados ontológicos nos quais modos de existência tornam-se possíveis, envolvendo subjetividade e alteridade. Defendemos, portanto, a urgência de estranhar a teleologia do discurso educacional que, ao planificar o espaço e quantificar o tempo, converte essa inalienável difração da política em expurgo da diferença. Longe da redenção, trata-

Doutor em Educação pela Universidade do Estado do Rio de Janeiro; Mestre em Educação pela Universidade Federal de Minas Gerais.

2 Mestre em Educação pela Universidade Federal do Rio de Janeiro; doutorando em Geografia pela Universidade Federal do Rio de Janeiro. 
se de reativar a importância vital da política curricular como participante ativa do devir do mundo sem o qual não haverá democracia possível.

Palavras-chave: Política Curricular. Difração. Relacionalidade Ontológica. Rede. Espaço-tempo.

Abstract: This article emerges from the broader intentions of a research-intervention project carried out in partnership with the municipal public network of Niterói at the same time that the city tries to respond to BNCC legal demands. From rounds of conversations with teachers in an extension course in order to contribute to the construction of the city's curriculum framework, we seek to configure a theoretical reflection on curriculum policy, modes of existence and diffraction. Situated as heirs of the tradition that criticized the distinction between implementation and formulation, we have developed the argument that instead of a curriculum going through a network, a network invariably goes through the curriculum. That is, a continuous topological dynamic comes alive, involving spatiotemporal variation. Anchored in feminist and queer studies of science and technology and by intersections of Gilles Deleuze's philosophy, we point out how a constitutive differentiation of politics exhibits a diffraction of time and space and, at the same step, constitutes ontological entanglements in which modes of existence render possible, involving subjectivity and otherness. We therefore defend the urgency of problematizing the teleology of educational discourse, which, by planning space and quantifying time, converts this inalienable diffraction of politics into a purge of difference. Far from redemption, it is about reactivating the vital importance of curriculum policy as an active participant in the becoming of the world without which there will be no possible democracy.

Keywords: Curriculum Policy. Diffraction. Ontological Relationality. Network. Spacetime.

Resumen: El artículo emerge de las intenciones más generales de un proyecto de intervencióninvestigación en asociación con la red pública municipal de Niterói al mismo tiempo que la ciudad responde a las demandas legales de la BNCC. Desde rondas de conversaciones con los maestros de un curso de extensión con la finalidad de hacer contribuciones a la construcción del marco curricular de la municipalidad, intentamos dibujar una reflexión teórica sobre la política curricular, los modos de existencia y la difracción. Ubicados como herederos de la tradición que criticaba la diferencia entre implementación y formulación, desarrollamos el argumento de que, en lugar de un currículo pasar por una red, una red pasa invariablemente por el currículo. Es decir, una dinámica topológica continua gana vida, implicando la variación espacio-temporal. Haciendo uso de estudios feministas y queers, de la ciencia y la tecnología y de intersecciones de la filosofía de Gilles Deleuze, señalamos que un aplazamiento constitutivo de la política exhibe una difracción de tiempo y espacio y, al mismo paso, constituye enredos ontológicos tornando modos de existencia posibles, involucrando, por supuesto, subjetivad y alteridad. Defendemos, así, la urgencia de cuestionar la teleología del discurso educativo que, al planificar el espacio y cuantificar el tiempo, convierte esta difracción inalienable de la política en exclusión de la diferencia. Lejos de la redención, tratamos de 
reactivar la importancia vital de la política curricular como participante activo en el futuro del mundo sin el cual no habrá democracia posible.

Palabras clave: Política Curricular. Difracción. Relacionalidad Ontológica. Red. Espacio-tiempo.

Recebido em 21 de fevereiro de 2020

Aceito em 17 de julho 2020

Publicado em 24 de setembro de 2020

\title{
1 IMPLEMENTAR, REFORMULAR, EMARANHAR
}

\begin{abstract}
De agora em diante, não há um orador nem mediador únicos. Não há um mestre sem contramestre. Não há univocidade. Cada um pode exprimir-se na sua própria língua e os destinatários dessas palavras podem recebêlas na sua. Depois de desatados os nós, restará apenas uma imensa linha. (MBEMBE, 2014, p. 20).
\end{abstract}

Comecemos pelo que mais ou menos sabemos: a Base Nacional Comum Curricular ganhou, em 2017, força de lei. De lá para cá, secretarias municipais de educação estão tendo que responder à interpelação de "adequarem", "implantar" ou "implementar" - para usar, não sem algum desconforto de nossa parte, verbos presentes no texto da resolução do Conselho Nacional de Educação (BRASIL, 2017) - os currículos àquilo previsto pelo documento que thes foi endereçado. Esse clima pairava no ar quando nossa pesquisa-intervenção ${ }^{4}$ em três municípios de regiões diferentes do país - Niterói/RJ, Cachoeira/BA e Rondonópolis/ MT - começou. De certa maneira, o projeto mais amplo que subsidia este artigo partiu de uma problematização das fantasias associativas entre qualidade da educação e projetos de currículo nacional (MACED0, 2016b). ${ }^{5}$

Nessa direção, seria preciso frisar que nossa entrada junto à Rede Municipal de Educação de Niterói, campo de interlocução que focalizaremos neste texto, foi marcada pelo anúncio constante de que a "reformulação curricular" em andamento - termo, desta vez, usado por nossas parceiras de pesquisa - não era uma resposta direta à BNCC nem sua tributária. Sua emergência florescia das demandas de professores/as, gestores/as e da própria secretaria quanto à necessidade de rever o referencial curricular da rede

3 S site da BNCC apresenta uma seção especifica intitulada Implementação com biblioteca de apoio, currículo de outros países e espaço para compartilhamento de práticas. Disponivel em: http://basenacionalcomum.mec.gov.br/implementacao.

4 Sobre o uso da noção de intervenção, ver Miller e Macedo (2018).

50 projeto contou com financiamento do CNPq por meio do edital de Pesquisa e Inovação em Ciências Humanas, Sociais e Aplicadas. Além disso, a tese de doutorado de Ricardo Scofano Medeiros é financiada com bolsa da CAPES. 
com notável inspiração no multiculturalismo (NITERÓl, 2011). É nessa paisagem específica, no atravessamento desses movimentos, que este artigo caminha. Passemos, assim, ao que desejamos: explorar os desafios de uma agenda de pesquisa sobre política de currículo ancorada em estudos feministas e queers da ciência e da tecnologia, complicada, igualmente, por intersecções da filosofia de Gilles Deleuze. ${ }^{6}$ Agenda desenvolvida, neste artigo, a partir do curso de extensão sobre produção curricular no qual estivemos envolvidos de maio a dezembro de 2019 em Niterói.

0 curso figurou como a primeira parte da parceria da pesquisa com a rede de educação básica do município e envolveu duas turmas com trinta vagas cada uma: uma com professoras ${ }^{7}$ da Educação Infantil e outra com docentes das duas etapas do Ensino Fundamental. As temáticas das rodas de conversa, que aconteceram uma vez por mês para cada turma, foram respectivamente as seguintes: políticas de avaliação, políticas de currículo, teorias de currículo, cultura e diferença e integração curricular. 0s temas foram selecionados a partir de uma conversa inicial com a equipe gestora da rede e de um primeiro encontro nomeado de Diagnóstico. Os dois últimos encontros foram reservados para a elaboração de uma proposta curricular para a Secretaria Municipal de Educação disparada a partir dos relatos das professoras contados nos encontros anteriores. Implicadas no processo, além das professoras de Niterói, professores/as e doutorandos/as de uma universidade federal e outra estadual também se revezaram para movimentar cada roda de conversa a partir de textos elaborados para tanto e enviados previamente.

Nós gostaríamos, entretanto, de driblar, com alguma licença, certo tom de relato de experiência sobre o curso, evitando, com isso, reviver "um sujeito depositário do humanismo, conhecedor e conhecível, no controle de suas intervenções no mundo." (MLLER; MACEDO, 2018, p. 951). Por efeito, não desejávamos usar nossa formação em currículo para auxiliar aquele grupo de professoras a descobrir ou elucidar algo sobre elas mesmas, e muito menos pretendíamos mediar, do alto de nossa expertise, o alcance de algum objetivo político maior. Ao menos para nós, o curso estava mais para criar um espaço de co-labor, no trocadilho proposto por De La Cadena (2015), de trabalhar juntos, sem o sonho do holismo, em um envolvimento múltiplo e diferencial, sem que, dessa maneira, precisássemos emular que todos nós teríamos os mesmos propósitos ou pressupostos, defenderíamos as mesmas opiniões para os problemas colocados ou trabalharíamos envolvidos do mesmo modo, ainda que sentíssemos entre nós alguma afinidade política - e elas foram muitas!

6 Embora este texto tenha sido escrito em parceria entre orientando e orientador, ambos operam com diferentes tradições teóricas para pensar a relação entre política de currículo, subjetividade e diferença. Nós optamos, assim, por não subsumir as diferentes ferramentas que usamos umas às outras, mas escolhemos manter intercessores conceituais de correntes distintas, ecoando uns nos outros.

7 Em virtude de as turmas terem sido majoritariamente compostas por mulheres, nós optamos por escrever professoras. 
Assim, nossa entrada se dá por meio de uma justaposição preliminar - e marcamos o caráter tentativo das formulações aqui apresentadas - de elementos disparadores do curso com um conjunto de questões mais amplas em torno de argumentar a favor de uma política de currículo situada, ecoando, simultaneamente, as "diferenças que tornaram possível uma conexão entre nós" (DE LA CADENA, 2015, p. 16). Para tanto, nós nos aproximamos daquilo que Jackson e Mazzei (2013, p. 269) nomearam, em um termo de tradução difícil, de plugging in, "para intervir em um processo a fim difratar o significado, ao invés de forcluí-lo." Movimento através do qual, um de nós já sugeriu (RANNIERY, 2018), remetemo-nos a uma espécie experimentação teórica com o próprio pensamento curricular.

Como ficará explícito, nossa experimentação segue particularmente insuflada pelo conceito de difração. Utilizada por Haraway (1997, p. 273), difração é uma "metáfora para outro tipo de consciência crítica no final de um milênio cristão bastante doloroso, comprometida em produzir diferença." Ao recorrer à difração, Haraway (1999) evoca um efeito ótico que, diferente da reflexão ou da refração - nas quais mudanças na direção da luz geram imagens deslocadas em que se reconhecem variações de um padrão inicial -, quebra a luz em variadas direções, criando padrões de interferência. Em suas palavras, "um modelo difrativo não indica onde aparecem as diferenças, mas onde aparecem os efeitos da diferença." (HARAWAY, 1999, p. १२6).

Nessa perspectiva, e apoiada em Barad (2010, p. 254), apoiada em Haraway (1999), mobiliza a difração para fazer algo mais do que uma metáfora em torno de repensar a filosofia ocidental moderna, intentando, por sua vez, abrir ontologicamente "o binário de escolhas obsoletas entre determinismo e livre arbítrio, passado e futuro." Em ressonância, sugere que a difração "não é meramente sobre diferenças, e certamente não é sobre a diferença em sentido absoluto, mas sobre a natureza emaranhada das diferenças que importam [...] A difração é uma prática material para fazer a diferença, para reconfigurar topologicamente conexões." (BARAD, 2007, p. 381). Na leitura que faremos, a difração tem vigorosos efeitos políticos ${ }^{8}$ pois "podemos entender padrões de difração - como padrões de difração que fazem diferença - como constituintes fundamentais que compõem o mundo." (BARAD, 2007, p. 72).

Sendo assim, a difração carrega a diferenciação ontológica aberta e relacional para o coração da política, "uma prática material de engajamento como parte do mundo em seu devir diferencial." (BARAD, 2007, p. 83). Um mundo do qual não se pode dissipar de uma vez por todas a normatividade e é - sem dela se descuidar -, ao mesmo tempo, repleto de "uma plenitude de possibilidades, uma cacofonia de convers(a)ções." (KIRBY, 2011, p. 88). Com essa

8 Não estamos desconsiderando as implicações éticas da difração, como várias autoras destacam - ver, a título de exemplo, De La Becassa (2017) -, incluindo a própria Barad (2008). Contudo, nós nos assentamos sobre a ideia de não restringir a difração a este terreno e, deste modo, esperamos não fundir ética e política. Entretanto, a insistência na relacionalidade ontológica coloca efeitos mútuos entre ambos os terrenos. 
inspiração, desejamos distender a herança, na qual fomos formados, de que a produção da política curricular desde a escola não poderia mesmo ser relegada a um produto de segunda ordem que vem após os fatos - a promulgação legal da BNCC, por exemplo - e que, embora respeitável, é, por vezes, soterrada pela tradição explicativa que toma a política curricular como emanada do e pelo Estado (LOPES; MACED0, 2011). Todavia, a questão, para nós, deixa de ser menos como políticas são colocadas em ação nas escolas, ao estilo do que, certa vez, sugeriu Ball, Maguire e Braun (2016). Isso porque, ao aceitar, tal como sugerem os autores, que a multiplicidade já está presente nas políticas educacionais, indicamos que a diferença é condição da política curricular acontecer.

Em termos difrativos, a produção de uma política é "o processo e o resultado de um processo ao mesmo tempo." (SEHGAL, 2014, p. 189). 0 problema com a diferença na política de currículo não é, então, uma questão de conhecimento ou de representação, mas de envolvimento com e para o mundo. Seus efeitos indicam que a política não somente se dá por relações de similaridade, nas quais a diferença pesaria como que separada, derivada de uma exclusão, mas também conectam e articulam "modos complexos e antagônicos de viver juntos." (BUTLER, 2017b, p. 14). Longe, pois, do consenso, argumentamos que a política curricular arrasta modos de existência em redes de perspectivas e, por isso, exige estranhar a teleologia do discurso educacional que planifica o espaço e quantifica o tempo. Procuramos, deste modo, fazer funcionar a proposição que dá título a este texto: muito antes de um currículo passar por uma rede, uma rede passa pelo currículo. Isto é, há redes dentro de uma rede: um emaranhado ontológico.

Logo, sustentamos que uma leitura topológica e multidimensional da política curricular (MACED0, 2016a), de uma paisagem que não se encerra em si, variante e variável espacial e temporalmente, necessitaria ser conectada a constituição de emaranhados ontológicos através dos quais subjetividade e alteridade se envolvem. Quando falamos em produção da política de currículo, "um campo intersticial, [...] o espaço-tempo de suspensão intervalar que liga e separa vidas para que possam existir" (RANNIERY, 2017a, p. 57), e insistimos no recurso à difração, é por defender que não há, como epígrafe de Mbembe (2014), univocidade. E, como corolário, de que a difração, ao ausentar a univocidade da política, mostra os efeitos das relações que nos envolvem, não apenas em termos de condicionamentos, mas também de invenção de alternativas - ou, de criação de possíveis no currículo, na convocação de Paraíso (2019).

Não extirpar "o poder formativo da política enquanto dimensão primordial do encaminhamento das expectativas humanas" (GRANDIN, 2011, p. 17) implica considerar como esses emaranhados ontológicos transformam a política curricular em termos de compromissos com a vida. Se o destino ético da vida é perseverar (ROLNIK, 2018), quem sabe, esse deslocamento difrativo do tempo e do espaço que extraímos das conversas durante o curso nos ajude a perceber a diferença, mesmo que mínima, entre "viver nas ruínas no neoliberalismo" (BROWN, 
2019) e apenas nelas sobreviver. Desse modo, nós esperamos ainda manter abertas as fronteiras não somente entre o que supostamente conta como currículo na hora de se fazer política, mas também o que conta como política na hora de se fazer currículo. ${ }^{9}$ Algo que exige uma atenção ao imponderável, como convida Macedo (2017b), e que preferimos chamar de atenção ao inominável, àquilo que nem nós, nem as professoras com as quais nos relacionamos tinham nome para descrever - e nem se pretendia ter -, mas que nem por isso desobriga de, ou, talvez em virtude disso, adensa um intenso e cuidadoso trabalho político.

\title{
2 PROFESSORA, ANTES DE DESMANCHAR A BRINCADEIRA, PODE TIRAR UMA FOTO?
}

\begin{abstract}
Eu não vi... 0 que é que ela não vê? Que 'alguma coisa' é essa [...] Inão vista]? Podemos dizer que é a disposição cuidadosa dos objetos que mostra a presença de um ponto de vista preciso da criança. Podemos dizer que é a 'alma' da criança - inteiramente transportada para a disposição dos objetos. Nos dois casos, teremos razão; ela vê os objetos, pois mexe neles e os arruma, o que ela não vê é o modo de existência deles sob o ponto de vista da criança, a arquitetura esboçada diante de seus olhos [...] No cosmos das coisas, há aberturas, inúmeras aberturas desenhadas pelos virtuais. Raros são aqueles que as percebem e lhes dão importância; mais raros ainda aqueles que exploram essa abertura em uma experimentação criadora. (LAPOUJADE, 2017, p. 43-44, grifo nosso).
\end{abstract}

A pergunta título que abre esta seção é oriunda do relato de uma professora, quando, na ocasião, o tema da roda de conversa era Integração Curricular. A professora contava que havia ficado curiosa quanto ao pedido de um de seus alunos: fotografar a disposição dos brinquedos na sala de aula. Em princípio, é tentador tomar a pergunta feita pela criança como se remetendo à brincadeira, aos brinquedos disponíveis em uma sala de aula, ou mesmo à presença do celular quase como se aquela interpelação demandasse que tudo isso fosse, por assim dizer, parte do currículo da Educação Infantil. Em alguma medida, contudo, tomaríamos imediatamente um resíduo de certa gramática política - que poderia ser caracterizada pela retórica centrada naquilo que entra e sai dos currículos (RANNIERY, 2017b) - como uma referência primeira. Nossa imaginação encenaria, então, um operador crítico com função ontológica que parece atuar justamente como um aparelho de captura, para evocar Deleuze e Guattari (2012), o que equivaleria a um esmagamento radical de um "campo perpétuo de interação" (DELEUZE; GUATTARI, 2012, p. 15).

\footnotetext{
Uma formulação inicial nesse sentido pode ser encontrada em Ranniery e Macedo (2018).
} 
É plausível, contudo, extrair da pergunta da criança e da curiosidade da professora - ou da curiosidade da professora gestada do encontro com a pergunta da criança e enunciada em uma conversa que a leva a rememoração - mais do que um repertório de materiais que deveriam estar presentes em todas as escolas para que outras crianças também pudessem brincar. A inquietação, parece-nos, é de outra ordem: a política curricular poderia dar as costas para a brincadeira? Talvez, sim. Talvez, não. E a pergunta-título aponta simultaneamente para ambas as respostas. Porém, quer seja de um modo, quer de outro, recorremos a essa cena do curso para aproximar brincadeira e política de currículo, não por seu conteúdo, mas por aquilo que Massumi (2017, p. 27) chama de poderes de variação, "a mais-valia de vida que ela [a brincadeira] desempenha."

De um lado, a busca por manter "uma força de passagem que induz uma mudança qualitativa na natureza da situação" (MASSUM, 2017, p. 17), movida, nesse caso, pela brincadeira, nem que seja para preservá-la em uma fotografia, mantém em circulação a possibilidade de "ter sua natureza transformada em outra inteiramente diferente da sua" (MALABOU, 2014, p. 31). Por outro lado, coexiste com a possibilidade sempre iminente do desmanche, a manobra, ainda que instável, que busca drenar, como um antibiótico, a "animação, a vivacidade - uma maisvalia de vida, irredutivelmente qualitativa, nivelada de forma ativa com o viver." (MASSUMl, 2017, p. 25). Dito de outro modo, da pergunta à curiosidade relatada, é como se fôssemos lançados a uma política de currículo tomada desde uma zona de indiscernibilidade "de coexistência e de concorrência, lentre] as máquinas de guerra de metamorfose e os aparelhos identitários do Estado, os bandos e os reinos, as megamáquinas e os impérios" (DELEUZE; GUATTARI, 2012, p. 25), e não a uma zona de indiferenciação. Como insiste Massumi (2017, p. 19), é uma zona de multiplicação do múltiplo, "onde as diferenças se unem ativamente" naquilo que escapa à conformação da política curricular pelo Estado, ou mesmo se ergue contra, ainda que agenciadas em relação e no mesmo campo topológico estatal.

Com essa evocação da brincadeira, queremos dar relevo a algo dessa conexão que é agenciado por diferenças mínimas, menores, quase inaudíveis, - a professora se surpreende com a pergunta da criança, não vendo, por alguns instantes, aquilo que a criança via - que não permitem antecipar nada sobre seus efeitos, o que não quer dizer que anulem a contingência da política, mas salienta que está sempre a se fazer rondar "uma questão de intensificação" (MASSUMI, 2017, p. 22). Neste mesmo movimento, estamos tentando dar alguma textura a algo dessa zona que dá passagem "ao limite, aos turbilhões e projeções" (DELEUZE; GUATTARI, 2012, p. 27), que é, sim, percebido pelas professoras, posto que "perceber não é observar de fora um mundo estendido diante de si [...]; é entrar num ponto de vista, assim como simpatizamos. Percepção é participação." (LAPOUJADE, 2017, p. 47). Todavia, essa percepção aparece como uma marca de um rumor sensível que permanece no ar, meio sem nome, meio sem rosto, só articulável, do ponto de vista da enunciação, em pequenos balbucios, para seguir com Rolnik (2018). É que, ali, no interior de um "conjunto de práticas e instituições por meio das quais uma 
ordem é criada, organizando a coexistência humana no contexto conflituoso produzido pelo político" (MOUFFE, 2015, p. 8), desdobram-se outras linhas afirmativas que, por vezes, não vemos, de difícil nomeação, e que, a despeito da cegueira, não deixam de estar diretamente implicadas na produção da política com seu "poder de mudança sem redenção, sem teleologia, sem outra significação que não seja a estranheza." (MALABOU, 2014, p. 26).

Não temos lá muita certeza ou segurança se será possível gerar uma “visibilidade que desloca a reabsorção consensual de todo o visível em seu sentido conhecido" (RANNIERY, 2017a, p. 61) e nem se estamos pedindo tanto. Porém, o que nosso trabalho entre e com histórias de professoras vem indicando é que já se está produzindo, ao menos, uma sensibilidade - e não um programa político, por certo - que desloca a política tal como conhecemos por meio de "novas configurações, novas subjetividades, novas possibilidades - lem quel até os menores cortes são importantes." (BARAD, 2007, p. 384). É, deste modo, que a difração da política curricular não se resume às consequências subsequentes das maneiras através das quais professoras e escolas interagem com e atuam em consequência ou à revelia de um texto ou documento político, como se o efeito seguisse a causa em uma cascata linear de eventos. Mais precisamente, é sobre a produção e relação entre modos de existência - tomando de empréstimo a distensão que Lapoujade (2017) realiza no trabalho de Étienne Souriau -, tendo em conta as materializações emaranhadas das quais fazemos parte (a brincadeira da criança, por exemplo). 0 que a difração traz à política é esta relacionalidade ontológica e o entrelaçamento diferencial - o (des)contínuo tornar-se e separar-se nos termos de Barad (2007) - como já implicados em qualquer produção curricular.

Nós estamos, deste modo, buscando nos deslocar de avalizar a conduta das professoras diante das cenas que relatam - uma fantasia humanista, diga-se de passagem, de "reduzir a subjetividade ao sujeito" (ROLNIK, 2018, p. 111) - para as a práticas precariamente localizadas em andamento, nas quais "nós" nunca somos entidades categoricamente separadas. Esse movimento escancara como estamos emaranhados nas questões com as quais nos envolvemos e somos envolvidos. Um dos efeitos do processo difrativo é, notam Coole e Frost (2010), a necessidade de desarticular o sujeito como origem da política. 0 que não deve ser entendido, de modo apressado, como anúncio da morte da política. Ao contrário, nossa deriva para recorrer à noção de modos de existência é por perceber que, para se efetuar e ganhar consistência nesse meio caudaloso da difração, a produção da política curricular passa por assumir que a "intensificação da realidade de uma existência tem sempre como correlato a afirmação de seu direito de existir, como esse direito não é mais atribuído por um fundamento soberano, lentão] é preciso conquistá-lo por outros meios" (LAPOUJADE, 2017, p. 103) e, acrescentaríamos, por meio de outros. No lugar de aderir à oposição ou à substituição do que quer que seja, a conquista desses meios de afirmação amplia o campo de 
produção da política curricular e realiza que "Inlinguém pode ser sem ser afetado" (MALABOU, 2014, p. 25). Ancoramo-nos, assim, nas palavras da professora Fernanda: ${ }^{10}$

\begin{abstract}
Eu tenho essa preocupação muito grande do currículo deixar a criança ser criança, porque primeiro ela precisa ser criança. Gente, ela já está na escola, já passa de 8 a 9 horas se você for fazer toda a conta. E têm muito disso, algumas verdades estão postas e nessa comunhão de dois professores eu não sei qual é verdade. Mas essa congruência, essa conversa, é ótima para a gente ter essa abertura realmente na escola. (informação verbal).
\end{abstract}

Caso nossa intuição esteja correta, o que uma pontuação dessas abre é que o "problema da existência não é o da sua facticidade, da sua irredutível contingência ou do seu absurdo. 0 problema é mais elementar: trata-se de existir realmente." (LAPOUJADE, 2017, p. 103). Isso porque, a questão colocada pela professora, tornada apenas precariamente enunciável pela sensibilidade ao inominável, se configura menos em duvidar "da existência de uma coisa do que do seu direito de existir." (LAPOUJADE, 2017, p. 84). Entretanto, como defender o direito à existência, sem que, com isso, tenhamos de defender um sujeito? Ou, para perguntar de outro modo, o que vem depois do sujeito?" Em um texto bastante conhecido, Foucault (2009) realiza um questionamento que nos auxilia. Grosso modo, ao argumentar que o autor é uma função da linguagem, não um sujeito individual, ${ }^{12}$ Foucault (2009, p. 294) pergunta o que a "regra do desaparecimento do escritor ou do autor permite descobrir?" e responde que "ela permite descobrir o jogo da função autor."

Em um uma deriva argumentativa, perguntamo-nos: o que a necessidade da afirmação do direito de existir leva a descobrir sobre o jogo da existência? É provável que nossa resposta seja outra pirueta: a afirmação do direito de existir permite trazer a tessitura política da existência e a tessitura existencial da política. É como se reativasse aquilo que Ettinger (2009, p. 9) chama de "campo psíquico transjetivo" ou como se liberasse "uma força de transformação transindividual” (MASSUMl, 2017, p. 17) já sendo partes da produção da política curricular. São esses laços transversais que tornam um modo de existência possível e por meio dos quais se encontram e não param de se atravessar, produzindo uma rica figuração do emaranhamento ontológico com os nós situados e singulares através dos quais uma política de currículo é difrativamente produzida. Há, contudo, um problema, apenas aparentemente indissolúvel, em toda essa movimentação: como reconhecer aquilo que não

10 Todos os nomes utilizados são fictícios.

" Entrevista de Jacques Derrida a Jean Luc-Nancy, na qual este último introduz essa pergunta. Ver, Derrida (1991).

12 Fazemos referência, aqui, à ideia de que "o sujeito costuma ser interpretado por aí como se fosse intercambiável com a 'pessoa' ou o indivíduo'. A genealogia do sujeito como categoria crítica, no entanto, sugere que o sujeito, em vez de ser identificado estritamente com o indivíduo, deveria ser descrito como categoria linguística, um lugar-tenente, uma estrutura em formação." (BUTLER, 2017a, p. 19). 
conseguimos nem nomear, mas que, paradoxalmente, existe bem na frente dos nossos olhos e, por vezes, aparece por meio de uma enunciação frágil e tentativa?

0 ponto, para seguirmos com Butler (2010, p. 168), é que o "reconhecimento é uma relação intersubjetiva, e, para um individuo reconhecer o outro, ele tem que recorrer a campos existentes de inteligibilidade." 0 reconhecimento - que, aqui, não é a recognição no sentido conferido por Deleuze (2018) -, complementa a autora, também pode ser "o lugar onde os campos existentes de inteligibilidade são transformados." (BUTLER, 2010, p. 168). Os mesmos campos que permitem o reconhecimento são aqueles que, contudo, podem excluir o direito de existir, mas que, apesar disso ou em virtude disso - já que se deve recorrer a eles -, podem ser transformados. A leitura que realizamos, portanto, consiste em aceitar que o direito de existir, e não a existência, depende do reconhecimento. Neste caso, relações ambivalentes instauradas por campos de inteligibilidade sustentam esse direito de uma forma que, ao fazê-lo, um modo de existência sempre arrasta consigo a transformação, a metamorfose ontológica do campo que, a princípio, não o reconhecia.

Este é o motivo pelo qual a inclusão da diferença pelo diferente (MACEDO, 2014; MEDEIROS; RANNIERY, 2018) revela-se insuficiente, para não dizer tautológica. Converte-se em redução ontológica - a criança como sujeito, a infância como cultura, a brincadeira como atividade pedagógica - ao reafirmar as divisões e trabalhar por adição, sem transformar o próprio solo, devorando a diferença para expeli-la como seu excesso. Nosso argumento começou, de fato, por assumir que diferir não é "sobre exterioridade radical, mas sobre separabilidade agencial [...], não é sobre diferenciar ou separar, mas, ao contrário, sobre fazer conexões e compromissos." (BARAD, 2007, p. 392). Quando a difração é introduzida na arena da política de currículo - que descrevemos como a prática mesma de produção curricular - a imagem do pensamento, para voltar aos termos de Deleuze (2018), da política se transforma - bem como o que pode ser considerado como ação política - em uma cena que já abduz uma sensibilidade crítica. Em tela, uma virtude da difração: colocar a questão da diferença como uma prática política que "consiste em expandir por turbulência" (DELEUZE; GUATTARI, 2012, p. 29) e não "está destinada a tomar um poder nem sequer um desenvolvimento autônomos" (DELEUZE; GUATTARI, 2012, p. 44). 0 que antes era o problema a ser resolvido diante da chegada da BNCC, remetendo a uma reflexão desde cima de um mundo perturbado por assimetrias e imposições de toda parte, torna-se uma zona intra-ativa diferentemente emaranhada na qual o mundo importa a todo o momento.

Em resumo, estamos sugerindo que nenhuma política de currículo escapa de ser articulada ou mesmo de ser avaliada - para ficarmos com o jargão da mensuração, mas, desta vez, desde uma posição de multiplicidade qualitativa, como nomearia Deleuze (1999), e não numérica -, de interferir e de ser envolvida nesses compromissos e conexões de diferenciação, mesmo que faça a contragosto. Essa entrada complica a política curricular 
ao afirmar que, em sua ordinariedade, não passa de "uma dança enlameada de múltiplos parceiros [que] não preexistem à sua intra-ação constitutiva em cada camada dobrada de tempo e espaço" (HARAWAY, 2008, p. 32). 0u, ao seguir o argumento de Kirby (2011, p. 89), a produção de uma politica curricular é invariavelmente difrativa porque a vida em geral (des) continuamente negocia "manter [...] tudo dentro."

Dessa maneira, nós utilizamos a pergunta-título desta seção para entrarmos nessa zona borrada de negociação a fim de abrir o imaginário político em direção a uma relacionalidade ontológica ao nível da subjetividade, posto que não há produção de política que não encadeie mutuamente modos de existência e materialidade. De tal maneira, se defendemos que a difração da política curricular não é apenas uma multiplicidade sem fim, ou regulada de indivíduos singulares que reinterpretam textos políticos, é para bloquear o retorno rápido a uma subjetividade encarnada como uma entidade fixa antes do relacionamento acontecer e não permitir capturar todo o emaranhamento de relações ontológicas por um só sujeito ou por um grupo de sujeitos.

Tudo isso nos sintoniza ainda mais com a visão de política de currículo emaranhada por redes, tal como Macedo e Ranniery (2018) exploraram, e como continuaremos a desdobrar na seção a seguir. Todavia, já se poderia afirmar, de partida, - e poderá não ser uma novidade - que nunca haverá um resultado final de uma política curricular, qualquer que seja. Em vez disso, seus tópicos somente ganham materialidade nas "teias emaranhadas que tecemos" (BARAD, 2007, p. 384). A prática difrativa dá a sentir uma queerização (RANNIERY, 2016), por assim dizer, de qualquer um e em todos os níveis da produção enredada de uma política curricular. Torce, enfim, a própria noção de diferenciação, fazendo da política situada nas e desde as escolas não um predicado de uma alguma noção fixa ou derivativa. ${ }^{13}$ Antes, dá relevo ao "emaranhamento espaçotempomaterializante" (BARAD, 2012, p. 42), no qual a diferença, para todos os efeitos, e sob o risco de soarmos repetitivos, "deriva de dentro, não fora" (BARAD, 2012, p. 42).

A despeito da nossa aproximação, crescem, portanto, as complexidades em torno da noção de rede, posto que as duas cenas que usamos nessa seção ganham contornos do que M'charek (2014, p. 30) chama de um objeto dobrado, os "modos intricados através dos quais se reúnem espaços e tempos heterogêneos." Assim, não é forçoso de nossa parte afirmar que não queremos, ao vincular tão intimamente política de currículo e ontologia por meio da difração, diminuir, de forma alguma, a necessidade de crítica aos constrangimentos normativos que a promulgação da BNCC pode engendrar. Entretanto, nossa insistência por um compromisso com a diferença deve-se em conceber a política curricular como o próprio

13 No caso da BNCC, não é a sua implementação que se negocia nas escolas, mas a BNCC é, ao mesmo tempo, aquilo que se negocia quanto apenas parte do que se negocia. 
emaranhamento do devir no mundo e recusar a ideia, por vezes tentadora, de que a produção de mundos teria se esgotado por meio da lei. ${ }^{14}$

\title{
3 UMA REDE DE PERSPECTIUAS
}

\begin{abstract}
Lidar com a gestão democrática não é fácil, é um desafio, e eu tenho que prestar atenção nisso o tempo todo, porque vira uma professora e fala assim: eu não achei isso democrático! Mas como assim? Nós decidimos na reunião o que a gente ia fazer, inclusive consultamos os pais. Essa decisão foi democrática. Agora, democrático também é respeitar a decisão da maioria. É complicado a beça, gente! Tem que estudar muito, que bom que a gente tem que estudar, isso só faz bem! (Adriana, professora da rede municipal de Niterói) (informação verbal).
\end{abstract}

A contenda relatada pela professora na roda de conversa sobre Política de Currículo é nosso ponto de entrada para retomarmos, nesta seção, a ideia de rede. Se uma política de currículo está longe de ser mero substrato a partir do qual, ou cenário no qual, relações de diferentes ordens se desdobram e transcorrem, a difração demanda que o espaço-tempo possa ser concebido de forma mais desafiadora, como "uma coreografia espaço-temporal generativa sempre em movimento." (MASSEY, 2015, p. 88). Noções correntes como "adaptar" ou "implementar" pressupõem uma direção de tempo e uma planificação do espaço que mereceriam ser, assim, problematizadas. Para tanto, somos obrigados a conceituar o espaço e de tempo "como aberto[s], múltiplo[s] e relacionalis], não acabado[s] e sempre em devir, [pois esse] é um pré-requisito, também, para a possibilidade da política." (MASSEY, 2015, p. 95). Essa dobradura do tempo e do espaço é parcialmente sentida nesses momentos de perturbação, nesses momentos de desentendimento, na expressão de Rancière (1996), que abrem como o "modo de apresentação [da política] não é homogêneo ao modo comum de existência dos objetos assim identificados." (RANCIERE, 1996, p. 107). 0 desentendimento, sugere Rancière (1996, p. 11), "não é o conflito entre aquele que diz branco e aquele que diz preto. $\dot{E}$ o conflito entre aquele que diz branco e aquele que diz branco, mas não entende a mesma coisa, ou não entende que o outro diz a mesma coisa com o nome de brancura."

14 Em Força de Lei, Derrida (2010) localiza o paradoxo da iterabilidade no coração da lei que, não podendo se fundar nem se conservar de modo puro, que não seja por meio de uma violência, "exibe e arquiva o próprio movimento de usa implosão, deixando no lugar o que se denomina um texto, o fantasma de um texto que, arruinado ele mesmo, ao mesmo tempo fundação e conservação, não chega nem a uma nem a outra, e fica ali, até certo ponto legivel e ilegivel, como a ruína exemplar que nos adverte singularmente acerca do destino de todo texto e toda assinatura na sua relação com o direito, isto é, necessária e infelizmente com certa polícia." (DERRIDA, 2010, p. 10, grifo nosso). 
Lido juntamente com a difração, o desentendimento - visto como a possibilidade simultânea dos interlocutores entenderem e não entenderem a mesma coisa com as mesmas palavras -, longe de apenas mudar de direção ou telos, nos lança para as transformações e rearticulações que, em nosso argumento, constituem a espessura do tempo e do espaço emaranhado da política curricular. Em um apanhado de perguntas sobre o que chama de redes políticas, Ball (2014) caracteriza uma problematização de um modo bem diferente do que realizamos, mais centrado em formas institucionais e de governança globalizada, que, contudo, gostaríamos de lançar mão. Afinal, em uma rede, "o que as setas significam? Que tipo de relações e/ou trocas elas representam? Elas são equivalentes? Qual é a força dessas relações? Qual é o sentido do fluxo? Como as relações e seus pontos fortes mudam ao longo do tempo?" (BALL, 2014, p. 33). Tais questões testemunham a complicação que transcorre por entre as veias de qualquer rede. Para ficarmos apenas em uma das questões levantadas, não seria sem propósito reiterarmos a curiosidade em sabermos o sentido do fluxo de determinada política. Germina na escola e chega até às Secretarias de Educação? Começa na sala de aula e chega à sala da direção? Irradia dos conselhos de classe para todo o restante da escola? É oriunda dos anseios familiares em relação ao desempenho dos alunos e alunas? Emana da compra de pacotes educacionais prontos em parcerias que borram as fronteiras entre o público e o privado? Ou aquilo que acontece nas escolas é pautado pelas avaliações externas que mais funcionam como políticas de indução curricular?

A resposta de Ball $(2014$, p. 32) nos parece interessante, uma vez que as redes políticas não só "desfocam as fronteiras entre Estado e sociedade, mas elas também expõem o processo de elaboração de políticas a jogos de poder particularistas". Nessas vias, o emaranhamento espaço-temporal é fundamental para recolocar a relação entre rede e política de currículo, desta vez, a fim de trabalhar com a "diferença para fazer diferença" (HARAWAY, 1997, p. 273). Um caminho poderia ser de o de imaginar, analogamente, uma rede de pesca: "um conjunto integrado e estruturado de fios, que formam uma trama ou malha; no encontro entre dois fios, eles se entrelaçam, formando um nó, o que dá estabilidade à rede (sem os nós, nem sequer haveria rede)." (SOUZA, 2016, p. 166). Contudo, logo que olhamos para uma rede podemos ver também um conjunto de interconexões e de "práticas contestáveis [na quall os parceiros nunca estão dados de uma vez por todas." (HARAWAY, 2008, p. 314). A imagem da rede de pesca pode bem ser explicativa, mas conforma muito rápido nossa imaginação à unidimensionalidade. Por outra via, estamos insistindo que não há distinção temporal e espacial entre a mediação de professores e escolas - o que Ball, Maguire e Braun (2016) chamariam de atuação - e uma política curricular específica. 0 que significa que a produção da política curricular não pode ser considerada ontologicamente distinta de um experimento de desentendimentos.

Dessa perspectiva, uma rede municipal de educação consistiria, certamente, em um conjunto de prédios, escolas e demais sedes administrativas que tornaria possível a 
distribuição de unidades escolares de tal ou qual maneira. Inseparável da rede, os documentos políticos endereçados a professores e escolas, os fluxos de capital e dinheiro, a alimentação, água, energia elétrica, conhecimento a ser ensinado, etc. - e estas eram questões que provocavam os relatos das professoras. Uma rede parece sempre remeter a outra rede indefinidamente: formam um emaranhado. Dito de outro modo, teríamos que levar seriamente em conta que, visíveis ou invisíveis, redes são compostas pelos mais diferentes materiais (FENWICK; EDWARDS, 2011) não redutíveis a atores humanos. Para, logo em seguida, assumirmos que esses emaranhados materiais-discursivos engendram aquilo que chamamos, na seção anterior, de uma marca sensível.

Dessa forma, por mais confuso e incoerente que seja, é crucial tomar que "vários tipos de redes mais do que humanas, enredadas umas nas outras" (FENWICK; EDWARDS, 2011, p. 712) são constitutivas da política. No entanto, isso não é suficiente para enfrentar rastros de sentido da política que tem como plataforma comum controlar desentendimentos por meio da "crença racionalista na viabilidade de um consenso universal baseado na razão" (MOUFFE, 2015, p. 11). 0 importante é como esses emaranhados, através dos quais um modo de existência vem à tona - e dos mundos a que pertencem -, já são difrativamente constituídos, de modo que o desentendimento não leva a separações absolutas. Ao invés disso, gera um estranhamento, um deslocamento que não destrói a possibilidade de correlação, mas a permite. E é esse vínculo, essa relação, que queremos afirmar por "política".

Em síntese, o que a rede nos coloca é menos a perspectiva diferente de alguém sobre algo - o sentido de democracia não seria o mesmo para uma e outra professora, por exemplo. Segue, então, que uma política curricular é situada, pois está sempre perturbada pela ingerência de que "não temos uma perspectiva sobre o mundo, pelo contrário, é o mundo que nos faz entrar em uma de suas perspectivas." (LAPOUJADE, 2017, p. 47). Em uma paráfrase possível, é a rede que nos faz entrar em uma de suas muitas perspectivas, em uma rede de perspectivas, portanto. Uma política curricular, assim, não se torna cada vez mais enredada na medida em que se desloca por diferentes contextos (BALL, 1994). Sua produção expressa, antes, a presença incontornável da difração espaço-temporal como seu elemento constitutivo, ativando, simultaneamente, o movimento de "pôr em xeque a unificação abstrata e universal como pré-condição de uma política que se quer pública." (MACED0; RANNIERY, 2018, p. 745). Nessa suspensão, tempo e espaço são enovelados, não simplesmente sob a fórmula de onde e quando a política acontece, mas, sim, sob os termos produtivos do espaço-tempo emaranhado como condição mesma da política.

Rever a noção de espaço-tempo, colocando-o como elemento constitutivo do desentendimento, requereria, deste modo, recolocar a própria conceituação do que chamamos de rede. Se, para Ball (2014), a rede é concomitantemente um método e um dispositivo conceitual, em perspectiva semelhante, uma mirada sobre a ideia de malha, de 
Ingold (2012), pode oferecer algum contributo para, ao invés de representar determinada realidade, pensarmos a rede afinada ao incalibrável processo de criação da vida inerente à política curricular, em sua dimensão impossível de métrica e quantificação, como Lemos e Macedo (2019) apontaram. Essa mirada tem por princípio continuar a bagunçar o intento de determinar um lócus específico de onde emanaria a política, isto é: quais são as direções de seus fluxos, de onde elas vêm e para onde elas vão. Assim, admitiríamos, co-extensivamente, que uma rede passa pelo currículo não somente porque não possui contornos limitados, mas também porque a relacionalidade ontológica abre para formas experimentais de criar vidas e mundos interconectados.

Tal ponderação alimenta nossa preferência quanto à ideia de malha. Pois, muito além de ser "uma técnica analítica para olhar a estrutura das comunidades de política e suas relações sociais" (BALL, 2014, p. 30), uma malha é composta por um emaranhado de "trajetórias que não param de se estender constitulindo] a textura do mundo" (INGOLD, 2012, p. 39), na qual questões sobre diferenças são sempre conjugadas com atenções para afetar e enredar. Com a malha, a política curricular não é um simples retrato de "uma superfície isotrópica sobre a qual todas as coisas estão embrulhadas nelas mesmas, fixadas em seus respectivos lugares, separadas dos movimentos que as trouxeram ali, pegas em uma rede finita, fechada." (INGOLD, 2015, p. 212). Imaginar, deste modo, uma rede aberta é condição para manter a sensibilidade ao inominável da alteridade ecoando, onde "natureza, cultura, corpos, textos - tudo se desdobra num campo de força de diferenciação sem limite." (ALAMM0, 2017, p. 927).

Ao aceitar a abertura dessas redes nas quais os processos educativos se dão, a diferença se encarna como o dínamo capaz de rearranjar formas pré-estabelecidas (PARAíSO, 2010). Isto posto, o imprevisível, no lugar de ganhar inteligibilidade como fator indesejado, congrega, como os relatos das professoras parecem apontar, vida e política de modo indissociável. Para tanto, deixamos de lado a vida enquanto um atributo ou direito que pudesse ser possuído por alguém, e, junto a lngold (2012, p. 27), a entendemos "enquanto capacidade geradora do campo englobante de relações dentro do qual as formas surgem e são mantidas no lugar." (INGOLD, 2012, p. 27). Logo, se pensarmos que a produção da subjetividade "habita o paradoxo entre duas experiências simultâneas, como sujeito e fora-do-sujeito" (ROLNIK, 2018, p. 60), poderemos, por conseguinte, liberar o imaginário de tomar a produção da política como centrada no indivíduo. A política de currículo ganha tons de figurar mais como um campo de relações entre modos de existência, sempre difratado por desentendimentos, acompanhado, por suposto, de sua dimensão espaço-temporal. Ou, nas palavras de Rancière (1996, p. 54), a "política não é feita de relações de poder, é feita de relações de mundos."

Nesses encontros inesperados, oriundos do cruzamento de distintas trajetórias, não há respostas para nomear o que conta como política ou ação política em um currículo. A incapacidade de "dar uma 'boa' definição dos procedimentos que permitem alcançar a 'boa' 
definição de um 'bom' mundo comum” (STENGERS, 2018, p. 446), ou de uma boa política de currículo que deveria ser comum a todos, é a base do dissenso que temos testemunhado nas rodas de conversa junto às professoras da rede municipal de Niterói. Pululam, ali, perguntas como: é possível elaborar um currículo para a rede inteira? Com escolas tão diferentes entre si, é justo um currículo comum? Esses questionamentos, além de serem indicativos da heterogeneidade espaço-temporal de trajetórias difratadas, apontam também para o fato de que fazer currículo e fazer política estão sob a insígnia do

\begin{abstract}
desconhecido que constitui esses mundos múltiplos, divergentes, articulações das quais eles poderiam se tornar capazes, contra a tentação de uma paz que se pretenderia final, ecumênica, no sentido de que uma transcendência teria o poder de requerer daquele que é divergente que se reconheça como uma expressão apenas particular do que constitui o ponto de convergência de todos. (STENGERS, 2018, p. 447).
\end{abstract}

Dito de outra forma, o que está em jogo não é uma ontologia única da política com variações locais que reintegram a diferença ao "paradigma do todo e da reconciliação" (DUQUE-ESTRADA, 2008, p. 22). 0 que torna essa história de produção de uma política curricular em parceria com uma rede municipal mais fascinante é aceitar que "há diferentes perspectivas de diferentes mundos - e não visões diferentes de um mesmo mundo." (COSTA, 2014, p. 71). Se não vivemos todos em um único mundo, não queremos dizer, com isso, e vale à pena insistir, que cada um de nós vive em mundos isolados e impenetráveis. Nós nos remetemos, aqui, à "implicação mútua e intersubjetiva" (MACEDO; RANNIERY, 2018, p. 749), desta vez, entre mundos e modos de existência. Esse contínuo atravessamento rearranja o espaço e o tempo da política como "a esfera de uma simultaneidade de dinâmicas, constantemente desconectada por novas chegadas, constantemente esperando por ser determinada (e, portanto, sempre indeterminada) pela construção de novas relações." (MASSEY, 2015, p. 160). Não duvidamos que nosso argumento possa soar em alguma medida exageradamente celebratório. Contudo, é esse "encontro dos heterogêneos" (RANCIĖRE, 1996, p. 44) que anda ameaçado pelo casamento voluptuoso das demandas neoliberais com demandas neoconversadoras e mesmo por justiça social na política curricular. ${ }^{15}$ Quando se retira o desentendimento, a política, enfim, desaparece. Desse modo, nós necessitamos pensar a produção da política curricular na qual o dissenso, quer dizer, uma rede difratada de perspectivas que não se cessam de se atravessar umas às outras, é parte do viver juntos, se desejamos responder e fazer jus à diferença.

15 Argumento explorado por Elizabeth Macedo em diferentes lugares e a partir de diferentes enfoques. Ver, a título de exemplo, além dos textos citados neste artigo, Macedo (2017a). 


\title{
4 DIFRATAR, EMARANHAR, COABITAR
}

\begin{abstract}
Como justificar por que as coordenadas de um quadro de referência específico devem ter precedência sobre outro? Como evitar a quietude política? Como trabalhar em direção a uma compreensão mais generosa da política da diferença, se diferenciar, discriminar, decidir e julgar parece envolver um ato inevitável de negação ou apagamento: 'Isto e não aquilo!'? (KIRBY, 2012, p. 198).
\end{abstract}

Chegada à seção final, gostaríamos que nossa argumentação fosse lida ao ritmo das perguntas de Kirby (2012), como quem buscou, nessas páginas, realizar uma compreensão mais generosa da relação entre diferença e política de currículo em uma paisagem marcada pela "implementação da BNCC". De fato, a pesquisa-intervenção em parceria com a rede municipal de educação de Niterói é assombrada por uma questão: é possível produzir política de currículo situada desde e na escola? Essa é uma pergunta urgente diante do estado que nos encontramos no terreno das políticas curriculares. Porém, seja qual for a resposta, nós propusemos enriquecer essa interrogação com uma leitura difrativa da política, unindo as dobras éticas dos modos de existência com a dimensão ontológica das redes e dos desentendimentos que não cessam de as atravessarem, nas quais "o outro repercute no eu como alteridade irredutível e o eu, sob a ação desse impacto, diz o outro." (CARDOZO, 2018, p. 395). Com efeito, existem inúmeros caminhos para a questão da produção da política curricular se nós pudermos abraçar os emaranhamentos ontológicos relacionais antes de nos apressarmos em analisar o funcionamento do que quer seja em uma gramática gerenciável. 0 que acontece se a produção da política curricular não passar de uma profusão de conversações ontológicas cruzadas? $\mathrm{E}$ se for esse mesmo o campo de força de articulações difratadas que "implementação da BNCC" insiste em reduzir?

Tatear por entre tantas perguntas nos levou a trazer duas ponderações. Ao invés de lutar pela coexistência das histórias das professoras e thes exigir representação e lugar na política, a afirmação da relacionalidade ontológica, de "ter o outro na pele" (BARAD, 2007, p. 392), transforma a imagem da cena política. Longe de aprender a criar campos de consenso, a produção de uma política curricular envolve a aprendizagem de uma sensibilidade a um terreno difrativamente compartilhado e coabitado. Nós trouxemos o desentendimento aos emaranhados ontológicos para insistir na existência de conflitos sem solução e, em virtude disso, que essas fricções produzem modos de conectar, "um modo de ter e dar lugar em relação, como uma forma de vida." (CARDOZO, 2018, p. 318). Este é um trabalho político de articulação, como Hall (1996) afirmou certa vez, sem garantias. Ao discutir sobre a coabitação, Butler (2017b) indica não priorizar o dentro ou o fora, o eu ou o outro e vincula os emaranhados ontológicos de histórias diferentes e ressoantes ao dinamismo espaço-temporal da habitação da política. Sendo assim, nossa preocupação com a difratar a política curricular 
aponta para a coabitação da diferença em movimento. Isso porque, "mais profundos do que as qualidades e extensões atuais, do que as espécies e as partes atuais, há os dinamismos espaço-temporais. Eles é que são os atualizadores, diferenciadores." (DELEUZE, 2018, p. 283).

0 plano das múltiplas relações ontológicas emaranhadas ressoa no espaçotempo da política porque o que chamamos de aberturas alternativas não é sinônimo de que algo diferente poderá acontecer. Por possibilidades alternativas, nós insistimos que uma "história diferente é sempre possível, a qualquer momento, aqui e agora" (SCHRADER, 2012, p. 125). 0 trabalho da difração acontece o tempo todo. As possibilidades estão sempre retornando a cada intra-ação, posto que "nós somos do universo - não existe nem dentro, nem fora” (BARAD, 2007, p. 396, grifo do autor). Esse acontecimento é incomensurável e o fato de não ser possível nomeá-lo propriamente não é somente em virtude de ocorrer em um tempo ou em um espaço que não pode ser pré-concebido. É porque constitui o próprio espaço-tempo difrativo da política curricular. A possibilidade de produção de uma política de currículo situada, ou melhor, de constante localização e disseminação da política implica em perturbação. Reconhecemos, entretanto, que tal ponderação não serve necessariamente para melhorar o cenário ou nos aliviar em face de qualquer texto político que se pretenda totalizante. Isso significa apenas que a produção de uma política curricular jamais pode se opor à transformação - mediação, tradução, "gesto que transforma o outro para mantê-lo com força de ressignificação de nós mesmos" (CARDOZO, 2018, p. 319) -, por mais que se tente e qualquer tentativa só denunciará a impossibilidade sempre a assombrar. Ou seja, o elo diferencial de como as relações de desentendimento são vividas e habitadas torna perceptível o esforço ontológico de viver juntos constitutivo à produção da política curricular.

Quando relaxamos a presunção de que o tempo é um fluxo irreversível de presentes em movimento, e que o espaço seria a acumulação de superfícies chapadas, a produção da política pode se tornar transformadora. Podemos, quem sabe, nos aproximar daquilo que Gabriel (2019) chamou de articulação insurgente na política curricular. Ainda que tenhamos, ao nosso modo, mostrado ressalvas quanto à ideia de que "agir politicamente significa [...] participação na produção das normas e da gestão das atividades ou tarefas que constituem la comunidade]" (GABRIEL, 2019, p. 1562), reconhecemos, no mesmo passo, que tal articulação "tira todos que dela participam do seu lugar de conforto." (GABRIEL, 2019 p. 1561).

Reconfigurada pela difração, a questão deixa de ser aspirar histórias das professoras a uma produção política própria em oposição ou à revelia de uma política curricular ${ }^{16}$. Passamos à percepção de que o que existe "é apenas intra-ação de dentro e como parte do mundo em seu tornar-se" (BARAD, 2017, p. 395) e, logo, "perturbação não é a

16 Criar condições para reconhecer a produção curricular das escolas e professores é uma tradição no pensamento curricular brasileiro articulada, em grande parte, pelas pesquisas nos/dos/com os cotidianos escolares, lideradas por Nilda Alves e Inês Barbosa Oliveira; pesquisas com as quais, certamente, temos nossas dívidas e heranças. 
questão" (BARAD, 2017, p. 395). 0 que importa é como esse inominável da difração vai tramando coabitação por se recusar às "marcas distintivas taxonômicas, que assentam a diferença ao modo do apartheid" (HARAWAY, 1999, p. 126). Algo que exige ecoar um imperativo político diferente, expresso no projeto mais recente de Haraway (2016), em como "permanecer com a encrenca". Sob seu eco, giramos nossa escuta para cenas que afirmam nunca haver um ponto de partida inocente para qualquer busca política, que "nós" estamos sempre enredados e que, através de marcas sensiveis, esse "nós" já está em curso na realização daquilo lançado por Lopes (2018, p. 111), a saber: "talvez seja possível ser de outro modo". Por fim, o que queremos enfatizar é que isso poderia ganhar uma dimensão vital na produção da política curricular antes que tudo vire ruína.

\section{REFERÊNCIAS}

ALAIM0, S. Feminismos transcorpóreos e o espaço ético da natureza. Estudos Feministas, v. 25, n. 2 , p. 909-934, maio/ago. 2017.

BALL, S. Educação Global S. A. Ponta Grossa: Editora UEPG, 2014.

BALL, S. Educational reform: a critical and post-structural approach. Buckingham: Open University Press, 1994.

BALL, S.; MAGUIRE, M.; BRAUN, A. Como as escolas fazem as políticas: atuação em escolas secundárias. Ponta Grossa: Editora UEPG, 2016.

BARAD, K. Nature's queer performativity. Women, Gender \& Research, v. 1, n. 2, p. 25-53, 2012.

BARAD, K. Performatividade pós-humanista: para entender como a matéria chega à matéria. Vazantes, v. 1, n. 1, p. 7-34, 2017.

BARAD, K. Quantum entanglements and hauntological relations of inheritance: dis/continuities, spacetime enfoldings, and justice-to-come. Derrida Today, v. 3, n. 2, p. 240-268, 2010.

BARAD, K. Queer causation and ethics of mattering. In: GIFFNEY, N.; HRD, M. Queering the non/human. Hampshire: Asghate, 2008.

BARAD, K. Meeting the universe halfway. Durham: Duke University Press, 2007.

BRASIL. Resolução CNE/CP n 2 de 22 de dezembro de 2017. Institui e orienta a implantação da Base Nacional Comum Curricular. Brasília, DF: Ministério da Educação, Conselho Nacional de Educação, 2017. Disponivel em: http://basenacionalcomum.mec.gov.br/images/historico/RESOLUCAOCNE_CP222DEDEZEMBRODE2017.pdf. Acesso em: 22 dez. 2019. 
BROWN, W. Nas ruínas do neoliberalismo: a ascensão da política antidemocrática no Ocidente. São Paulo: Politeia, 2019.

BUTLER, J. A vida psíquica do poder: teorias da sujeição. Belo Horizonte: Autêntica, $2017 a$.

BUTLER, J. Caminhos divergentes: judaicidade e crítica do sionismo. São Paulo: Boitempo Editorial, $2017 b$.

BUTLER, J. Conversando sobre psicanálise: entrevista com Judith Butler. Entrevista concedida a Patrícia Porchat Pereira da Silva Knudsen. Estudos Feministas, v. 18 n. 1, p. 161 - 170, jan./abr. 2010.

CARDOZO, M. Tradução e o (ter) lugar da relação. In: LOPES, A.; SISCAR, M. (org.). Pensando a política com Derrida. São Paulo: Cortez, 2018. p. 285-322.

COOLE, D.; FROST, S. Introducing new materialisms. In: COOLE, S.; FROST, S. (ed.). New materialisms: agency, ontology, politics. Durham: Duke University, 2010. p. 1-43.

COSTA, C. L. Equivocação, tradução e interseccionalidade performativa: observações sobre ética e prática feministas descoloniais. In: BIDASECA, K. et al. (org.). Legados, genealogías y memorias poscoloniales: escrituras fronterizas desde el Sur. Buenos Aires: Godot, 2014. p. 273-307.

DE LA BECASSA, M. P. Matters of care: speculative ethics in more than human worlds. Minneapolis: University of Minnesota Press, 2017.

DE LA CADENA, M. Earth beings: ecologies of practice across Andean worlds. Durham: Duke University Press, 2015.

DELEUZE, G. Bergsonismo. São Paulo: Editora 34. 1999.

DELEUZE, G. Diferença e Repetição. Rio de Janeiro: Paz e Terra, 2018.

DELEUZE, G.; GUATTARI, F. Mil Platôs: capitalismo e esquizofrenia vol 5. São Paulo: Editora 34, 2012.

DERRIDA, J. "Eating Well," or the Calculation of the Subject'. In: CADAVA, E.; CONNOR, P.; NANCY, J. (ed.). Who Comes After the Subject? Nova York: Routledge, 1991. p. 96-119.

DERRIDA, J. Força da lei. São Paulo: Martins Fontes, 2010.

DUQUE-ESTRADA, P. C. Sobretudo o perdão - impossibilidade, alteridade, afirmação. In: DUQUE-ESTRADA, P. C. (org.). Espectros de Derrida. Rio de Janeiro: NAU, 2008. p. 13-38.

EITINGER, B. Fragilization and resistance. Studies in The Maternal, v. 1, n. 2, p. 1-31, 2009.

FENWICK, T.; EDWARDS, R. Considering materiality in educational policy: messy objects and multiple reals. Educational Theory, v. 61, p. 709-726, 2011. 
FOUCAULT, M. 0 que é um autor? In: M0TTA, M. B. (org.). Ditos \& escritos III: estética, literatura e pintura, música e cinema. Rio de Janeiro: Forense Universitária, 2009. p. 264-298.

GABRIEL, C. T. Currículo e construção de um comum: articulações insurgentes em uma política institucional de formação docente. E-curriculum, v. 17, n. 4, p. 1545-1565, 2019.

GRANDIN, G. The Last Colonial Massacre. Chicago: The University of Chicago Press, 2011.

HALL, S. The problem of ideology: Marxism without guarantees. In: MORLEY, D.; CHEN, K. Critical dialogues in culture studies. Londres: Routledge, 1996. p. 25-46.

HARAWAY, D. Las Promesas de los monstruos: una política regeneradora para otros inapropiados/bles. Política y Sociedad, n. 30, p. 121-163, 1999.

HARAWAY, D. Modest_Witness@Second_Millennium.FemaleMan@__Meets_OncoMouse ${ }^{\text {TM}}$. London: New York: Routledge, 1997.

HARAWAY, D. Staying with the trouble. Durham: Duke University Press, 2016.

HARAWAY, D. When species meet. Minneapolis: University of Minnesota Press, 2008.

INGOLD, T. Estar vivo. Rio de Janeiro: Vozes, 2015.

INGOLD, T. Trazendo as coisas de volta à vida: emaranhados criativos num mundo de materiais. Horizontes Antropológicos, ano 18, n. 37, p. 25-44, jan./jun. 2012.

JACKSON, A.; MAZZEI, L. Plugging one text into another: thinking with theory in qualitative research. Qualitative Inquiry, n. 19, v. 4, p. 261-271, 2013.

KIRBY, V. Initial conditions. Differences: a journal of feminist studies, v. 23, n. 23, p. 197-205, 2012.

KIRBY, V. Quantum anthropologies. Durham: London: Duke University Press, 2011.

LAPOUJADE, D. As existências mínimas. São Paulo: $n-1,2017$.

LEMOS, G.; MACEDO, E. A incalibrável competência socioemocional. Linhas Críticas, v. 25, p. 57-73, 2019.

LOPES, A. Sobre a decisão política em terreno indecidivel. In: LOPES, A.; SISCAR, M. (org.). Pensando a política com Derrida. São Paulo: Cortez, 2018. p. 83-116.

LOPES, A.; MACEDO, E. Contribuições de Stephen Ball para os estudos de políticas de currículo. In: BALL, S.; MAINARDES, J. (org.). Políticas educacionais: questões e dilemas. São Paulo: Cortez, 2011. p. 248-282.

MACEDO, E. Currículo, cultura e diferença. In: DE ALBA, A.; LOPES, A. (org.). Diálogos curriculares entre Brasil e México. Rio de Janeiro: EDUERJ, 2014. p. 83-103. 
MACEDO, E. Por uma leitura topológica das políticas curriculares. Archivos Analíticos de Políticas Educativas, v. 24, n. 26, p. 1-23, 2016 a.

MACEDO, E. Uma alternativa às políticas centralizadas: formar professores e produzir currículo nas escolas. Projeto de pesquisa e intervenção inovadora apresentado ao Edital Apoio à pesquisa e à inovação em Ciência Humanas, Sociais e Sociais Aplicadas do CNPq. Rio de Janeiro: Universidade do Estado do Rio de Janeiro, 2016b.

MACEDO, E. As demandas conservadoras do movimento Escola Sem Partido e a Base Nacional Curricular Comum. Educação \& Sociedade, v. 38, p. 507-524, 2017 a.

MACEDO, E. Mas a escola não tem que ensinar? Conhecimento, reconhecimento e alteridade na teoria do currículo. Currículo sem Fronteiras, v. 17, n. 3, p. 539-554, set./dez. $2017 \mathrm{~b}$.

MACEDO, E.; RANNIERY, T. Políticas públicas de currículo: diferença e a ideia de público. Currículo sem fronteiras, v. 18, n. 4, p. 739-759, 2018.

MALABOU, C. Ontologia do acidente. Desterro: Cultura e Barbárie, 2014.

MASSEY, D. Pelo espaço: uma nova política da espacialidade. Rio de Janeiro: Bertrand Brasil, 2015.

MASSUM, B. 0 que os animais nos ensinam sobre política. São Paulo: n-1 Edições, 2017.

MBEMBE, A. Sair da grande noite: ensaio sobre a África descolonizada. Luanda: Pedago, 2014.

M'CHAREK, A. Race, time and folded objects: the HeLa error. Theory, Culture \& Society, London, v. 31, n. 6, p. 29-56, 2014.

MEDEIROS, R.; RANNIERY, T. Geografias da criação: currículo, espaço e diferença. In: FERREIRA, C.; MACEDO, E. (org.). Currículo e diferença. Belo Horizonte: CRV, 2018.

MLLER, J.; MACEDO, E. Políticas públicas de currículo: autobiografia e sujeito relacional. Práxis Educativa, v. 13, n. 3, p. 948-965, set./dez. 2018.

MOUFFE, C. Sobre o político. São Paulo: Martins Fontes, 2015.

NITERÓl. Portaria FME n 085, de 12 de fevereiro de 2011. Institui na Rede Municipal de Ensino, as Diretrizes e os Referenciais Curriculares e Didáticos Prefeitura Municipal de Niterói. Niterói: Fundação Municipal de Educação, 2011. Disponivel em: http://www.educacaoniteroi.com.br/wp-content/uploads/2016/04/PORTARIA-FME-085-2011.pdf. Acesso em: 22 dez. 2019.

PARAÍSO, M. Diferença em si no currículo. Cadernos de Pesquisa, v. 40, n. 14, p. 587-604, 2010. 
PARAÍSO, M. 0 currículo entre o que fizeram e o que queremos fazer de nós mesmos: efeitos das disputas entre conhecimentos e opiniões. E-curriculum, v. 17, p. 1414-1435, 2019.

RANCIĖRE, J. 0 desentendimento: política e filosofia. São Paulo: Editora 34, 1996.

RANNIERY, T. Currículo, socialidade queer e política da imaginação. Teias, v. 18, n. 51, p. 52-67, 2017 a.

RANNIERY, T.; MACEDO, E. Políticas do vivivel: diferença, teoria e democracia por vir. In: LOPES, A.; OLIVEIRA, A.; OLIVEIRA, G. (org.). Os gêneros da escola e o (im)possível silenciamento da diferença no currículo. Recife: Ed. UFPE, 2018. p. 21-50.

RANNIERY, T. No meio do mundo, aquendar a metodologia: notas para queerizar a pesquisa em currículo. Práxis Educativa, v. 11, n. 2, p. 332-356, 2016.

RANNIERY, T. "Sexualidade na escola”: é possível ir além da máquina de diferentes? In: MACEDO, E.; RANNIERY, T. (org.). Currículo, sexualidade e ação docente. Petrópolis: DP et Alli, 2017b. p. 213-238.

ROLNIK, S. Esferas da insurreição. São Paulo: n-1, 2018.

SCHRADER, A. Haunted measurements: demonic work and time in experimentation. Differences, v. 23, n. 3, p. १19-160, 2012.

SEHGAL, M. Diffractive propositions: reading alfred north whitehead with Donna Haraway and Karen Barad. Parallax, v. 20, n. 3, p. 188-201, 2014.

SOUZA, M. Os conceitos fundamentais da pesquisa sócio-espacial. Rio Janeiro: Bertrand Brasil, 2016.

STENGERS, I. A proposição cosmopolítica. Revista do Instituto de Estudos Brasileiros, n. 69, p. 442-464, 2018.

Endereço para correspondência: Avenida Pasteur, 250, Urca, Campus da Praia Vermelha, Rio de Janeiro, Rio de Janeiro, Brasil; t.ranniery@gmail.com 